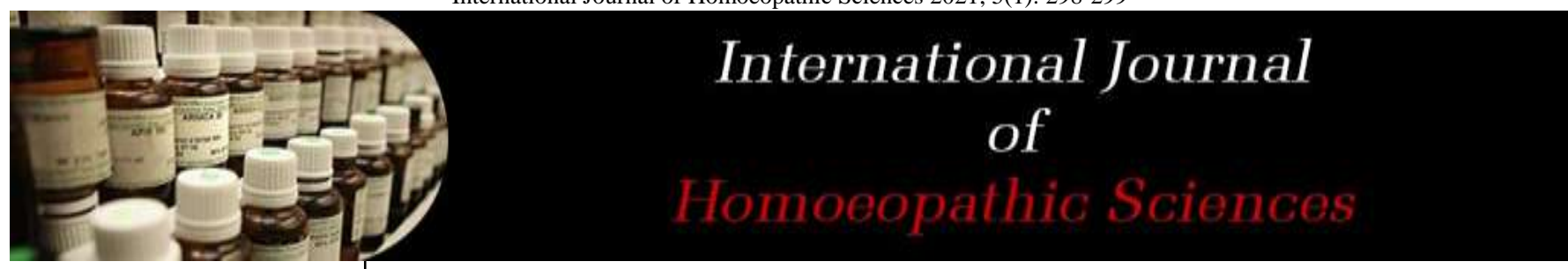

E-ISSN: 2616-4493 P-ISSN: 2616-4485 www.homoeopathicjournal.com IJHS 2021; 5(1): 298-299 Received: 17-12-2020 Accepted: 25-01-2021

Dr. Archana B Dahat MD Part-I, Organon of Medicine, Guru Mishri Homoeopathic Medical College, Shelgaon, Jalna, Maharashtra, India

Corresponding Author: Dr. Archana B Dahat MD Part -I, Organon of Medicine, Guru Mishri Homoeopathic Medical College, Shelgaon, Jalna, Maharashtra, India

\section{Insight to cosmetology and homoeopathic treatment}

\author{
Dr. Archana B Dahat
}

DOI: $\underline{\text { https://doi.org/10.33545/26164485.2021.v5.i1e.330 }}$

\section{Abstract}

Nowadays everyone in this world is conscious about their looks. Everyday companies are launching new products and are in the race of advertising their products. All of us are using these products without knowing their side effects. Use of products should be according to their, if not used according to the skin type then it may cause side effects or skin allerigies. As we are not aware of these allergies at times it becomes chronic. Homoeopathic methods are the best methods of treatments which treats from the root. In this article we are going to discuss few remedies to treat skin allergies caused due to regular use of cosmetics.

Keywords: Homoeopathic treatment, cosmetology, plant use, herbalist

\section{Introduction}

What is Cosmetology?

Cosmetics are topically applied products that are used to beautify, cleanse, or protect hairs, skin, teeth, or complexion ${ }^{[1]}$. Countries around the world see to it that the products are safe for the workers handling them, the environment and for the use of consumers.

Cosmetics should not contain any drug ingredients that may affect the structure or function of skin. However division of cosmetics \& drugs is not always clear as there are many products available that have two intended uses.eg. An antidandruff shampoo is a cosmetics because it is used to clean hair and scalp but it also contains the drug to treat the scalp \& dandruff. Such products must comply with the requirements for both cosmetics and drugs ${ }^{[2]}$.

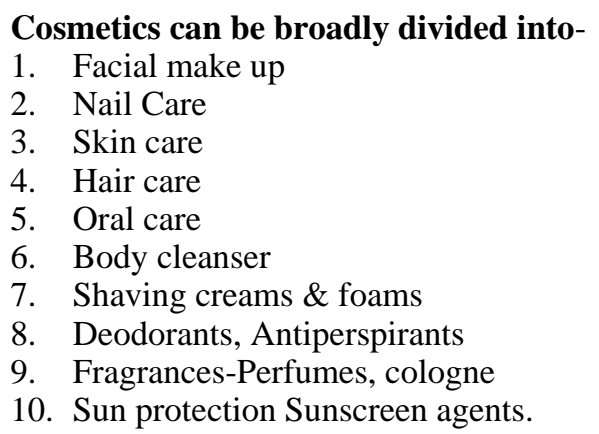

\section{Cosmetic allergy?}

As we all can see that cosmetics play an important role in our daily life. In an average every women is using cosmetics daily, so it not surprising that reactions to these products are quite common. Although the prevalence of allergies in general population is unknown, several studies shows that upto $10 \%$ of population who have some type of reactions to cosmetics over a period of time ${ }^{[3,11]}$.

This figure may be much more as many mild reactions occurring at home are self diagnosed $\&$ often self treated. An allergy to a cosmetic can produce a wide range of reactions.
1. Irritant Contact Dermatitis
2. Allergic Contac Dermatitis

3. Photo Contact Dermatitis

Some very common symptoms are -

1. Rash

2. Redness

3. Swelling 
4. Itching

5. Hives like breakout

\section{How allergies are to be known ${ }^{[4]}$ and ${ }^{[6]}$}

1. Patch Test: Can help you to identify the chemicals in cosmetics that your skin has become allergic to. It involves applying a small amount of cosmetics to your back \& observes the skin's reaction over several days.

2. Repeat Open Application Testing (ROAT): Can be used to confirm the relevance of reactions in cases of doubt.

\section{Tips to Prevent Cosmetics allergies ${ }^{[5]}$}

1. Limit number of beauty \& skin products.

2. Use of products suitable to skin type.

3. Avoid sharing Cosmetics.

4. Check expiry date.

5. Don't mix multiple products esp. Shampoo.

6. Choose products of short list of ingredients.

7. Apply perfume on clothes not on skin.

8. Choose the product free hypoallergenic fragrance.

\section{Treatments ${ }^{[7]}$}

Functional Foods: Two of these products are pre biotics and Probiotics.

Yoga: Yoga is an alternative therapy for allergy ${ }^{[8,9]}$ and ${ }^{[10]}$.

\section{Homoeopathic Management}

1. Graphities: An excellent remedy for many kinds of, but those very clear symptoms.

2. Apis mell: Best to treat the rash due to allergic reaction that itch burns and stings especially if it is hot out. Its a great natural remedy for allergic reactions where there is puffy swellings \& redness ${ }^{[12]}$.

3. Rhus Tox: It treats skin rashes that mimic those caused by that pant. It includes intense itching tickling, burning, pricking blisters surrounded by red skin ${ }^{[13]}$.

4. Mercurius: Great by rashes caused by poison or bacterial infections.

5. Sulphur: works well for rashes that are extremely itchy $\&$ feeling burning $>$ cold ${ }^{[14]}$.

6. Urtica Uerns: Big Blotches of skin that stings badly.

7. Sepia: Good for rashes with blisters on skin has turned yellow or brown. Good remedy for psoriasis, herpetic eruptions on lips and nose.

8. Selenium: Vesicular eruptions, dry scaly eruptions ${ }^{[15]}$.

9. Silicea: Dry and itch violently.

10. Natrum Carb: Dry skin eruptions.

\section{References}

1. https://en.wikipedia.org/wiki/Cosmetology

(last accessed on 14.02.21)

2. https://www.drmansoorali.com/cosmetology-treatment/ (last accessed 14.02.21)

3. https://www.fda.gov/cosmetics/cosmeticingredients/allergens-cosmetics (last accessed 14.02.21).

4. https://www.medicinenet.com/cosmetic_allergies/articl e.htm (last accessed 14.02.21)

5. https://pubmed.ncbi.nlm.nih.gov/15554734/ (last accessed 14.02.21)

6. Matura M, Goossens A, Bordalo O, et al. Patch testing with oxidized R-(+)-limonene and its hydroperoxide fraction. Contact Dermatitis 2003;49(1):15-21. [PubMed] [Google Scholar]
7. https://www.webmd.com/allergies/cosmetics

(last accessed 14.02.21)

8. https://www.allergyandasthmaclinicalcenters.com/blog/ can-yoga-really-help-treat-skin-allergies (last accessed 14.02.21)

9. https://www.stylecraze.com/articles/6-yoga-poses-tofight-skin-problems/(last accessed 14.02.21).

10. https://www.oprah.com/health/yoga-for-allergy-relief (last accessed 14.02.21).

11. Milady standard cosmetology by Catherine M. Frangie.

12. Boerick's Materia medica. Adi BS. Efficacy of homoeopathic medicines in chronic low back pain: a clinical study. International Journal of Alternative and Complementary Medicine 2020, 17-20.

13. Allens key note.

14. https://www.healthline.com/health/beauty-skincare/sulfur-for-acne

15. https://jamanetwork.com/journals/jamadermatology/arti cle-abstract/524452 